weight of the baby and increased neonatal mortality. Experimental studies have confirmed that condensates of tobacco smoke induce cancer in laboratory animals.

Now, rightly or wrongly, the Tobacco Research Council has accepted two main aims-firstly, to find the formula for a "safe" or "safer" cigarette ; and, secondly, to find ways of distinguishing individuals who are more susceptible than average to the harmful effects of smoking. These aims are constructive both from the point of view of the industry, which wishes above all to continue selling tobacco, and from the point of view of a large section of the public, who wish to continue smoking. But how realistic are the aims ? On the basis of present knowledge a completely safe cigarette seems to be out of the question. On the other hand, a safer cigarette (made of tobacco which yields the minimum of " $\operatorname{tar}$ ") and advice to smokers on how to reduce the risk to their health (choose cigarettes with an efficient filter, throw away a long butt $)^{5}$ have been feasible for several years already, and progress in these directions should be accelerated. It is likely that individuals do differ in susceptibility to the various effects of tobacco, though not in an absolute sense. Research into this is justified, but there are no real leads yet in the case of susceptibility to respiratory disease. The suggestion that smokers who develop a cough early in their smoking careess are also more likely to develop lung cancer $^{6}$ is certainly open to question. ${ }^{7}$

Who then should do what? Until it has had time to diversify its interests, and while it is so vulnerable to change in tobacco sales, it is unrealistic to expect the tobacco industry to make decisions that will cut its own throat. In the long run its only hope is that through the efforts of the Tobacco Research Council and of research generally knowledge will be acquired that makes the continued sale of tobacco justifiable. In the meantime only the Government and the general public are in a position to act. The progressive banning of advertising and other sales promotion procedures is within the Government's power, and is long overdue. Moreover, the general public is now ready to accept the progressive restriction of smoking in public places.

With regard to education, there is certainly a need to make factual information more widely available, though no advice can be so good as "Do not smoke." Epidemiological surveys have consistently shown that the risk of lung cancer in cigar and pipe smokers is less than that in cigarette smokers. But laboratory evidence shows that the condensate from cigar smoke is more carcinogenic for mouse skin than that from cigarette smoke. Thus, as M. C. Pike and F. J. C. Roe recently pointed out, ${ }^{5}$ there is insufficient evidence for actually recommending a cigarette smoker simply to change to pipe or cigars. They write: "Only if the change resulted in a reduction of both inhaling, and/or total tobacco consumption, could benefit be expected. Such a reduction is likely to be easier in the case of changing to pipe or large cigars, both of which are physically very different from cigarettes from the point of view of holding in the hands or mouth. However, the popularization of small, cigarette-sized cigars may carry the danger that smokers will smoke them in the same way, and in the same amount, as cigarettes."

Most people agree that it is extremely important to persuade young people not to start smoking. Here, however, the Government may perhaps be wise in proceeding slowly because so little is known of how best to tackle the issue. On the other hand, there is already good evidence that if parents or school-teachers wish their children to be non-smokers they are far more likely to achieve this end by their personal example than by exhortation or threats. Above all, doctors have a responsibility in this matter. Until the medical profession clearly and obviously accepts this responsibility, the Government will have a plausible excuse for its inertia.

\section{Electrical Anaesthesia}

Electrocution may result in unconsciousness. The possibility of converting this phenomenon into a safe, controllable, and immediately reversible form of general anaesthesia has attracted a number of investigators. ${ }^{1}$ The first human experiments were carried out by S. A. N. Leduc in 1902,2 and an important stage was reached in 1961 when J. D. Hardy and his collaborators ${ }^{3}$ reported the successful performance of surgical operations in two patients under electrical general anaesthesia.

The solution of some of the practical problems has outstripped any advances in the comprehension of what is happening during electrical anaesthesia, for such improvements in technique as have been evolved seem mostly to be the result of empirical trial and error. Indeed, an astonishing variety of waveforms, frequencies, and methods of applying the current have been used. ${ }^{4}$ Many of the investigations have been carried out on animals such as the dog and rabbit, but inferences from them are not necessarily true of man. Resistance to the narcotic effects of electricity is shown by many primates, including man, and in an effort to overcome it most workers have been forced to discard simple in favour of compound waveforms. Random or arrhythmic frequencies have also been tried. Despite trials of these and many other variations, including multiple electrodes, no particular combination appears to have a clear superiority.

The complications of electrical anaesthesia are not confined to the central nervous system. R. C. Knutson and colleagues ${ }^{3}$ abandoned the electrical narcosis which they were using to anaesthetize psychiatric patients, because of the frequency and severity of such cardiovascular complications as hypertension and irregularities of cardiac rhythm. Alterations in respiratory rhythm and even respiratory arrest have also been observed. The latest clinical report comes from N. L. Wulfsohn, ${ }^{6}$ who describes electrical anaesthesia in 11 patients undergoing relatively minor and brief surgical operations. Each patient had pethidine and promethazine premedication. The first few patients had a barbiturate as well as a relaxant and were intubated. In the last four cases of his series, as confidence was gained, no additional drugs were given during the operation. Anaesthesia was adequate and the only complications were slight hypertension and some muscle tremors. One patient had epileptic fits eight hours postoperatively, an event that underlines the need for much more fundamental knowledge of the physical effects of electrical currents traversing the brain.

Though the production of anaesthesia by electrical means is a possibility, many basic problems have yet to be solved before its use can be generally endorsed. Perhaps one day

1 Brit. med. F., 1961, 1, 566.

2 Leduc, S. A. N., Arch. d'Electr. Med., 1902, 10, 769. A. A. A. Amer. med. Ass., 1961, 175, 599 .

- Smith, R. H., Tatsuno, J., and Zouhar, R. L., Curr. Res. Anesth., $1967,46,109$.

s Knutson, R. C., Tichy, F. Y., and Reitman, J. H., Anesthesiology. 1956, 17, 815 .

- Wulfsohn, N. L., S. Afr. med. F., 1967, 41, 238. 
it will find a place alongside conventional methods now in use when its indications, technicalities, and complications have been much more clearly defined, but it seems unlikely to supplant them for a long time yet.

\section{Total Replacement of the Knee}

Rheumatoid arthritis and osteoarthritis both commonly damage the knee, and neither can be halted reliably. Thus a painful, stiff, and often unstable knee is a frequent outcome. No surgical procedure can at present restore full painless movement and stability, but theoretically total excision of the joint and its replacement with a prosthesis could do this. The problem of the design and implantation of such prostheses is partly surgical, partly biomechanical.

Three prostheses are now in use in Great Britain-one designed by B. Walldius ${ }^{1}$ in Norway, and one by L. G. P. Shiers $^{2}$ and one by G. K. $\mathrm{McKee}^{3}$ in Britain. All in their present versions are cobalt-chrome hinges attached to stems introduced into the medullary cavities of the tibia and femur. Because they are to some extent under trial, and because their implantation has sometimes met with surgical difficulties, they have usually been employed for patients with advanced disease who are not expected to return to full activity. As might be expected of such patients, they do not regain full function of the knee, but pain is diminished and the knee may be moderately mobile for some years after the operation. It was impossible to be sure, though, on the basis of this experience, that these devices would withstand many years of relatively normal use.

To test prostheses rigorously in clinical practice would be both hazardous to the patient and time-consuming. Machines have therefore been developed in two laboratories in England which will simulate the mechanical environment of the hip and knee. In these conditions the working lifetime of a prosthesis can be shortened by continuous use, and its response can be studied as it wears out. At the Royal National Orthopaedic Hospital the biomechanics unit under J. T. Scales has developed a simulator in which particular attention has been paid to the hip. ${ }^{4}$ A second machine has been designed in the biomechanics unit of the Mechanical Engineering Department at Imperial College, London, and with this work has started on the knee.

Laboratory testing is quicker, safer, and-with respect to the mode of failure of the bearing itself-more informative than clinical testing, but it has the great disadvantage that the behaviour of soft tissues and changes in living bone cannot be simulated. Two design requirements for total-replacement prostheses lend themselves in particular to laboratory testing. These are, firstly, the biological acceptability and mechanical efficiency (i.e., the biomechanics) of the bearing, and, secondly, with certain reservations, the biomechanics of the bond between the bearing and bone.

1 Walldius, B., Acta orthop. scand., 1960, 30, 137

2 Shiers, L. G. P., f. Bone ft Surg., 1960, 42B, 31 .

- McKee, G. K., unpublished.

Scales, J. T., Duff-Barclay, I., and Burrows, H. J., Proceedings of a Symposium on Biomechanics and Related Bio-Engineering Topics, Charnle ed, Kenedi, R. M., p. 205. London.

- Goodman, L. S., and Gilman, A., The Pharmacological Basis of Therapeutrcs, 1965, 3rd ed., pp. 1030 and 1407. New York

' Leidholt, J. D., and Gorman, H A., f. Bone ft Surg., 1965, 47 A, 1414.
With regard to the bearing itself, only two combinations of material have so far proved to be acceptable experimentally and clinically - a cobalt-chrome alloy on itself ${ }^{1}$ and highdensity polyethylene on stainless steel..$^{5}$ At Imperial College $\underline{\underline{T}}$ bearings suitable for the knee will be tested in these two combinations, and other materials will be studied if both $\stackrel{\odot}{\varnothing}$

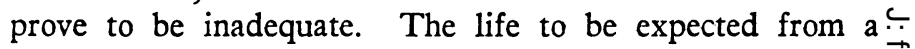
prosthetic knee constructed of either combination is unknown, $\underset{\vec{\rho}}{\overrightarrow{0}}$ but it is hoped that studies in the laboratory may afford a guide.

As the bearing wears out, friction rises, and particles and $\frac{\bar{\sigma}}{\frac{\sigma}{\sigma}}$ solutes are produced. Rising friction throws an increasing $\varrho$ load on to the bond between prosthesis and bone, and might be expected gradually to loosen the prosthesis. Thus measure- $\vec{\circ}$ ments of friction will provide a basis for preferring one design to another. Wear particles are deposited in the tissues $\vec{\omega}$ round cobalt-chrome prostheses and appear (in the short $\frac{\sigma}{\sigma}$ term) to be inert. Their long-term effect is unknown. Equally unknown (in relation to total-replacement prostheses) iv is the rate of production and biological effect of soluble salts $\mathrm{G}$ of chromium and cobalt. It is known, however, that these ions may be toxic. ${ }^{6}$ As to plastic materials, Teflon particles $\stackrel{N}{N}$ are known to produce locally a very undesirable foreign-body 욱 reaction. ${ }^{57}$ For these reasons it is planned to examine wear $\mathrm{N}$ particles and solutes produced in the laboratory, and this $v$ information will form another criterion of clinical acceptability.

At the hip a loose prosthesis is painful, and hence the bond $\overrightarrow{\mathscr{G}}$ between the prosthesis and bone is crucial to the success of the implant. The clinical success so far achieved at the hip has been attributed to the use of a quick-setting acrylic (polymethylmethacrylate) as a filling-agent between the prosthesis and the bone. ${ }^{8}$ The problem of bonding the prosthesis to bone is in some ways more difficult at the knee. This is $\stackrel{2}{\overrightarrow{7}}$ because, firstly, lateral and rotatory movements do not occur $\frac{0}{3}$ at the bearing (as they do in the hip), so that loads producing lateral bending and torsion must be borne entirely by the bond; and, secondly, the direction of the loads applied to the femoral component may vary through a right-angle (or more) when weight is taken on the flexed in contrast to the extended knee. Though so far satisfactory at the hip, it cannot therefore be assumed that polymethylmethacrylate will 8 prove to be satisfactory in the long term at the knee. While a bond which is satisfactory in the laboratory may sub- 을 sequently fail clinically for biological reasons, laboratory $\mathrm{N}$ studies should eliminate mechanically unsuitable bonds.

it is to be hoped that further engineering and surgical study will make total replacement of the knee a more routine $\mathrm{N}$ surgical procedure. Combined engineering and surgical స్ట work of this kind will surely make a valuable contribution to medicine-perhaps especially to orthopaedics-in the 0 future.

\section{Public Health Dispute}

At a special meeting on 17 May (Supplement, p. 132) the B.M.A. Council decided that sanctions should be introduced at once on behalf of public health medical officers in their dispute with the Management Side of Whitley Committee C. This decision was taken after Council had heard an account of the previous day's emergency meeting of the Public Health 